\title{
THE ROLE OF THE LIVER IN GLUCOSE AND LIPID METABOLISM IN OBESITY
}

\section{ULOGA JETRE U METABOLIZMU GLUKOZE I LIPIDA U STANJU GOJAZNOSTI}

\author{
Julijana Stanimirović1, Milan Obradović ', Zoran Gluvić2, ${ }^{2}$, Esma R. Isenović1,4
}

\section{Summary}

The liver plays a vital role in metabolic homeostasis and represents a major site for complex regulation of substrates (carbohydrates, lipids, and proteins) by insulin and other hormones. The significance of liver metabolic functions in many pathophysiological conditions is highlighted over the past decades. Mechanisms of obesity-induced metabolic disturbance in the liver are the topic of numerous research studies. Metabolic and hormonal changes which are caused primarily by visceral obesity lead to hepatic lipid accumulation. Increased prevalence of obesity and the development of metabolic syndrome contribute to pathophysiological changes in the liver and development of non-alcoholic fatty liver disease (NAFLD), one of the most common diseases in Western societies. In this review, we discussed most recent literature data related to the role of the liver in glucose and lipid metabolism in obesity.

Key words: glucose, lipids, liver, metabolism, obesity

\section{Sažetak:}

Jetra ima važnu ulogu u održavanju metaboličke homeostaze i predstavlja mesto kompleksne regulacije metabolizma supstrata (ugljenih hidrata, lipida i proteina) od strane insulina i drugih hormona. Proteklih decenija ističe se značaj metaboličkih funkcija jetre u brojnim patološkim stanjima. Mehanizmi kojima gojaznost dovodi do poremećaja metaboličkih procesa u jetri su danas predmet mnogobrojnih istraživanja. Metaboličke i hormonske promene koje su posledica prevashodno visceralne gojaznosti, dovode vremenom do nagomilavanja lipida u jetri. Povećana učestalost gojaznosti i razvoj metaboličkog sindroma doprinose pojavi patofizioloških promena u jetri i razvoju nealkoholne bolesti masne jetre (NAFLD), jednoj od najčešćih bolesti jetre u zapadnoevropskim zemljama. U ovom preglednom članku razmotrili smo najnovije literaturne podatke koji se odnose na ulogu jetre u metabolizmu glukoze i lipida u stanju gojaznosti.

Ključne reči: glukoza, gojaznost, jetra, lipidi, metabolizam

UvoD

Pored glavne uloge u detoksikaciji organizma, jetra ima važnu ulogu u održavanju metaboličke homeostaze i predstavlja mesto kompleksne regulacije metabolizma supstrata (ugljenih hidrata, lipida i proteina) od strane insulina i drugih hormona. Kao glavni regulator metabolizma energetskih supstrata, jetra preuzima nutrijente iz digestivnog trakta portnom venom, iz sistemske cirkulacije hepatičnom arterijom i iz limfnog sistema (1). Nakon preuzimanja, nutrijenti se u jetri metabolišu, a potom se kontrolisano oslobođaju u cirkulaciju (2). Proteklih decenija ističe se značaj metaboličkih funkcija jetre u brojnim patološkim stanjima (3). Jetra je organ koji je najviše izložen nakupljanju lipida u gojaznosti. Povećana učestalost gojaznosti i razvoj metaboličkog sindroma doprinose pojavi patofizioloških promena $\mathrm{u}$ jetri i razvoju nealkoholne bolesti masne jetre (NAFLD), jednoj od najčešćih bolesti jetre u zapadnoevropskim zemljama. NAFLD povećava podložnost jetre akutnim poremećajima u funkciji i može dovesti do razvoja ciroze i karcinoma jetre $(4,5)$.
MetabolizAM gLU KoZE U JETRI

Jetra ima jedinstvenu ulogu u kontroli metabolizma ugljenih hidrata održavajući koncentraciju glukoze u opsegu normalnih vrednosti, ekspresijom brojnih enzima koji se alternativno aktiviraju u zavisnosti od porasta ili pada koncentracije glukoze u krvi.

Nakon intestinalne apsorpcije, glukoza putem portne cirkulacije dospeva u jetru, a potom u sistemsku cirkulaciju. Koncentracija glukoze u cirkulaciji predstavlja razvnotežu između sinteze glukoze u jetri i preuzimanja glukoze od strane perifernih tkiva (uglavnom skeletnih mišića) (6). Sinteza glukoze u jetri je regulisana mehanizmom povratne sprege koja uključuje direktan efekat glukoze, tj. kada se poveća koncentracija glukoze u krvi, sinteza u jetri se smanjuje i obrnuto (7). Kompleksnija regulacija metabolizma glukoze uključuje $\alpha$ i $\beta$ ćelije pankreasa, koje odgovaraju na koncentraciju glukoze u plazmi tako što modifikuju sekreciju glukagona i insulina. Tokom postprandijalne faze koncentracija glukoze $u$ krvi raste i približno 10-25\% unete glukoze preuzimaju hepatociti $(8-10)$. Ulazak glukoze u ćeliju odvija se uz pomoć proteina nosača koji olakšavaju transport gluko- 
ze kroz ćelijsku membranu i oni su identifikovani kao članovi familije GLUT (do sada opisano 14 GLUT izoformi) (11). Iako su sličnih struktura, svaki član GLUT familije je specifično distribuiran po tkivima i podložan je specifičnim regulatornim mehanizmima, da bi se zadovoljile potrebe različitih tkiva. GLUT su u hepatocitima prisutni u unutarćelijskim depoima i u plazma membrani (12). GLUT2 je najzastupljenija GLUT izoforma u jetri (13 - 15); ima visok kapacitet, a nizak afinitet za glukozu. Transkripcija GLUT2 gena je istovremeno regulisana glukozom (16) i lipogenim faktorom, proteinom koji se vezuje za sterol regulatorni element (SREBP; engl. sterol regulatory element-binding protein) -1C (17), te kontrola transkripcije GLUT2 gena predstavlja mogući korak na putu ka glukolipotoksičnosti. Za razliku od GLUT4, koji se eksprimira u mišićnom i masnom tkivu, ekspresija i aktivnost GLUT2 je nezavisna od delovanja insulina. U hepatocitima se preuzeta glukoza fosforiliše do glukozo-6-fosfata u prisustvu glukokinaze (GCK, engl. glucokinase). Glukozo-6-fosfat se dalje uključuje u proces glikolize ili se koristi za sintezu glikogena, u zavisnosti od stanja metabolizma. U stanju gladovanja, jetra obezbeđuje energiju organizmu razgradnjom glikogena već 2-6 časova nakon obroka, dok tokom produženog gladovanja u jetri započinje de novo sinteza glukoze (glukoneogeneza) (18).

Insulin ostvaruje svoje efekte na fluks glukoze u jetri direktnim i indirektnim mehanizmima $(19,20)$. Direktni efekti insulina se dalje mogu podeliti na akutne efekte insulina koji dovode do brzog smanjenja sinteze glukoze u jetri (21) i hronične efekte insulina kojima se reguliše ekspresija ključnih enzima glukoneogeneze (22). Inidirektni efekti insulina na oslobađanje glukoze iz jetre uključuje supresija lipolize, inhibicija sekrecije glukagona $(23,24)$ i aktivacija nishodnih puteva hipotalamusa (25). Efekat insulina i drugih hormona na transport glukoze u jetri se ostvaruje preko signalnog puta supstrata receptora za insulin 1 (IRS, engl. Insulin Receptor Substrate)/fosfatidilinozitol 3 kinaze (PI3K, engl. Phosphoinositide 3-Kinase)/ protein kinaze B (Akt, engl. protein kinase B) $(26-28)$. Fosforilacija Akt dovodi do translokacije unutarćelijskih vezikula koje sadrže GLUT proteine na plazma membranu, što dalje olakšava preuzimanje glukoze u tkiva $(29-31)$.

\section{METABOLIZAM LIPIDA U JETRI}

Metabolizam lipida započinje u želucu mehaničkom emulzifikacijom i hidrolizom u prisustvu enzima lipaze, a potom se nastavlja u lumenu tankog creva u prisustvu enzima i žučnih kiselina. Zdrava jetra je krucijalna za apsorpciju lipida u tankom crevu jer se žučne kiseline sintetišu u hepatocitima i oslobađaju u žučni kanal, a potom u crevo, i dalje vrše emulzifikaciju lipidnih kapi omogućavajući njihovu hidrolizu od strane enzima lipaze (1).
Dobijeni produkti varenja lipida se apsorbuju u enterocite uz pomoć žučnih kiselina. Dalje se apsorbovani produkti resintetišu u enterocitama i pakuju u lipoporoteinske partikule - nascentni hilomikroni, koji ulaze u limfne sudove abdomena, a potom u cirkulaciju dva sata nakon unosa hrane (32). Nascentni hilomikroni u cirkulaciji gube dva glavna apoproteina (apoA-I i apoA-IV), koji bivaju zamenejni sa apoE i apoC-II. ApoC-II aktivira adipocitnu lipoproteinsku lipazu (LPL), koja olakšava digestiju triglicerida ( $\mathrm{Tg}$ ) (iz hilomikrona) na masne kiseline i glicerol (33). Masne kiseline se delimično preuzimaju iz cirkulacije i skaldište u adipocitima ili hepatocitima, dok ostaci hilomikrona ponovo ulaze u krvotok. ApoE potom prepoznaju receptor lipoproteina male gustine (LDL, engl. Low-Density Lipoprotein) na membrani hepatocita, protein koji je u vezi sa LDL receptorom (LRP; engl. LDL receptor-related protein) i skevendžer receptor $\mathrm{B} 1$, koji olakšavaju preuzimanje ostataka hilomikrona u jetru. U jetri se ostaci hilomikrona konačno razlažu unutarćelijskim lizozomima, i njihov glicerol, masne kiseline, holesterol, aminokiseline i fosfatni ostaci se metabolišu i recikliraju u nove lipoproteine veoma male gustine (VLDL, engl. Very-Low-Density Lipoprotein), koji se transportuju u cirkulaciju. Deo VLDL se razlaže na LDL i masne kiseline u perifernim tkivima. Jetra kontroliše koncentraciju holesterola u krvi uklanjanjem LDL i sintezom VLDL (3). Lipoproteini visoke gustine (HDL, engl. High-Density Lipoprotein) prikupljaju holesterol, glicerol i masne kiseline iz krvi i transportuju ih u jetru.

Masne kiseline u jetri potiču od endogene lipogeneze, oslobađaju se iz lizozoma u procesu autofagije ili potiču od plazma pula slobodnih masnih kiselina (SMK), koje se aktivno preuzimaju iz cirkulacije. U zavisnosti od stanja metabolizma, masne kiseline se ili prevode $\mathrm{u} \mathrm{Tg}$ i skladište, ili se brzo metabolišu u procesu $\beta$-oksidacije masnih kiselina, koji predstavlja predominantni izvor energije tokom gladovanja. Lipogeneza u jetri podrazumeva de novo sintezu masnih kiselina od acetil-koenzima A (CoA) ili malonil-CoA u reakciji koju katalizuju acetil-CoA karboksilaza (ACC, engl. acetyl-CoA carboxylase) i sintaza masnih kiselina (FAS, engl. fatty acid synthase). Elongacija lanaca masnih kiselina zahteva prisustvo nikotinamid adenin dinukleotid fosfata (NADPH) kao redukujućeg agensa, koji vodi poreklo iz puta pentozo fosfata. $\mathrm{S}$ obzirom da masne kiseline i njihovi metaboliti uzrokuju lipotoksičnost ćelija i promovišu sintezu reaktivnih oblika kiseonika (ROS, engl. reactive oxygen species), one se skladište u vidu $\mathrm{Tg}$, koji su relativno inertna jedinjenja. $\mathrm{Tg}$ se dalje skladište u lipidne kapi ili se uključuju u sintezu VLDL. Plazma pul SMK potiče od lipolize u adipocitima, koja se uglavnom dešava u stanju gladovanja. Lipolizu u adipocitima stimulišu kateholamini, natriuretični peptidi i glukagon, dok je uglavnom inhibira insulin.

Transport SMK u ćelije jetre je strogo kontrolisan proces. Mehanizmi transporta SMK u ćeliju nisu potpuno 
razjašnjeni, ali je poznato da SMK ulaze u hepatocite difuzijom ili posredstvom transmembranskih proteina (34). Do sada su u jetri identifikovana tri transportera koji olakšavaju transport SMK: protein plazma membrane koji vezuje masne kiseline (FABP, engl. fatty acid binding protein) (35), polipeptid za trasport masnih kiselina (FATP, engl. fatty acid transport polypeptide) (36) i tranlokaza masnih kiselina (FAT/CD36, engl. fatty acid translocase) $(34,37)$. Najviše izučavan protein asociran sa membranom, koji učestvuje u transportu SMK u hepatocitima je FAT/CD36. Stanje rezistencije na insulin (IR, engl. Insulin Resistance), koje je karakteristično za gojaznost i metabolički sindrom, praćeno je povećanom lipolizom $\mathrm{u}$ adipocitima, dovodeći do povećanja koncentracije SMK u plazma pulu nezavisno od nutritivnog statusa organizma (38). U tom slučaju hepatociti preuzimaju SMK olakšanim transportom (posredstvom transmembranskih proteina) pre nego difuzijom (39). Stoga su transporteri SMK u fokusu istraživanja NAFLD u okviru kojih je i identifikovana njihova raznolikost. Studije su pokazale da je povećana translokacija FAT/CD36 proteina na plazma membranu hepatocita $\mathrm{u}$ gojaznosti povezana sa razvojem IR i dijabetes melitus tipa 2 (T2DM, engl. type 2 diabetes mellitus) $(1,40,41)$.
PoremeĆAJ METABOLIZAMA GLUKOZE I LIPIDA U GOJAZNOSTI

Mehanizmi kojima gojaznost dovodi do poremećaja metaboličkih procesa $\mathrm{u}$ jetri su danas predmet mnogobrojnih istraživanja (42). Metaboličke i hormonske promene koje su posledica prevashodno visceralne gojaznosti, dovode vremenom do nagomilavanja lipida u jetri. Smatra se da pojačano oslobađanje lipida iz visceralnog masnog tkiva u gojaznosti povećava koncentraciju SMK u portnoj cirkulaciji (43). Periferna tkiva nisu u dovoljnoj meri osetljiva na insulin, smanjujući na taj način korišćenje glukoze kao izvora energije, što za posledicu ima povećanje glukoze u cirkulaciji i njenu dostupnost za druge metaboličke procese, uključujući sintezu SMK (44). Neto efekat insulina na adipocite $\mathrm{u}$ fiziološkim uslovima je povećano preuzimanje SMK iz lipoproteina i smanjeno oslobađanje u cirkulaciju (45). Međutim, u stanju IR dešava se suprotno, što za posledicu ima povećanu koncentraciju SMK u cirkulaciji (46). U tom slučaju, jetra, kao i drugi organi, bivaju izloženi visokim koncentracijama SMK, koje se moraju ukloniti iz cirkulacije. U zdravom organizmu jetra se brzo prilagođava pojačanom dotoku SMK u postprandijalnoj fazi njihovom brzom esterifikacijom (47). Još nije potpuno

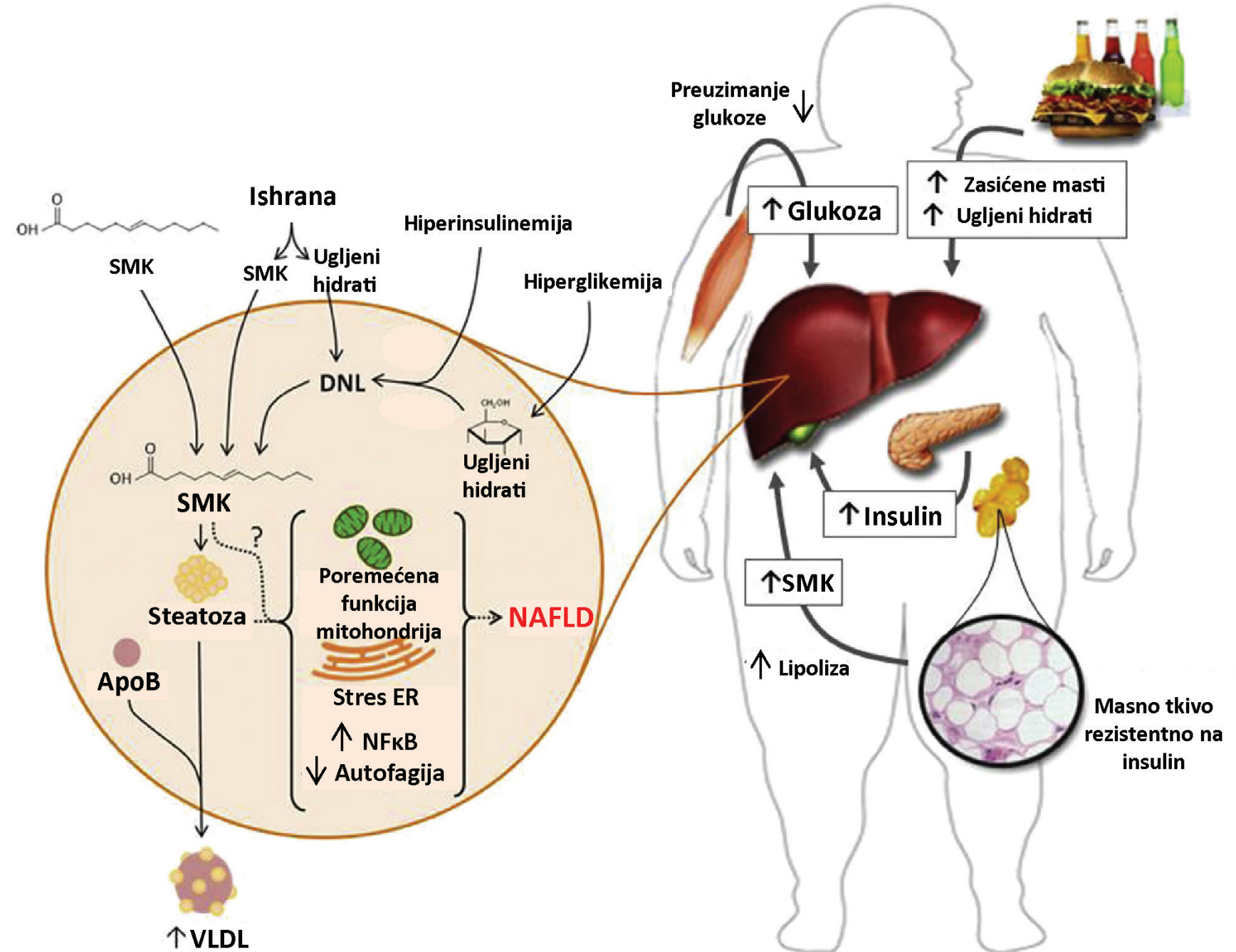

Slika 1. Metabolizam glukoze i lipida u gojaznosti. Apo-B - apolipoprotein B; DNL - de novo lipogeneza; ER - endoplazmatični retikulum; NFkB - nuklearni faktor -kB; SMK - slobodne masne kiseline; NAFLD - nealkoholna bolest masne jetre. Preuzeto i modifikovano iz $(57,58)$. 
razjašnjeno zašto jetra skladišti lipide. Smatra se da kada se prekorači kapacitet jetre za ukljanjanje SMK (u vidu njihove sekrecije ili oksidacije), jetra ih skladišti u vidu Tg (48). Međutim, povećana sinteza Tg ne može da kompenzuje dotok velikih količina SMK u jetru tokom dužeg vremenskog perioda (49), što direktno doprinosi razvoju IR u jetri, steatoze jetre i NAFLD (50 - 53). Studije pokazuju da gojaznost i posledično skladištenje SMK u vidu Tg u jetri predstavljaju važne faktore rizika za razvoj steatoze jetre i NAFLD (42). Takođe, hronično povećanje $\beta$-oksidacije SMK u mitohondrijama, dovodi do disfunkcije mitohondrija (54), inflamatornog odgovora (aktivacija Kupferovih ćelija) i lipoapoptoze hepatocita $(55,56)$.

Glavne karakteristike IR u jetri su povećana glukoneogeneza i lipogeneza, smanjeno preuzimanje glukoze u jetri i smanjena lipoliza (59 - 63). IR predstavlja stanje $\mathrm{u}$ kome periferna ciljna tkiva ne mogu u punoj meri da odgovore na fiziološke koncentracije insulina u cirkulaciji, pa stoga dolazi do smanjenog korišćenja glukoze kao izvora energije i povećanja nivoa glukoze u krvi, tj. hiperglikemije $(44,64-67)$. U početnom stadijumu razvoja IR, da bi se postigle fiziološke vrednosti glukoze, pankreas pojačano luči insulin te dolazi do kompenzacije IR povećanjem koncentracije insulina u cirkulaciji tj. hiperinsulinemije $(63,68)$. Iako hiperinsulinemija može da kompenzuje nastalu hiperglikemiju u nekoj meri, takođe može dovesti i do pojačanog dejstva insulina u tkivima koja zadržavaju normalnu osetljivost na insulin (53). Nakon perioda kompenzatorne hiperinsulinemije ipak dolazi do poremećaja funkcije $\beta$-ćelija pankreasa, nedovoljnog lučenja insulina i poremećaja u metabolizmu lipida i glukoze u ćelijama (69).

Smanjena sekrecija insulina, u kombinaciji sa rezistencijom na njegovo delovanje, rezultira T2DM, razornoj bolesti koja dostiže proporcije epidemije. Takođe, podatak da više od $90 \%$ gojaznih pacijenata sa T2DM boluje od NAFLD ukazuje na blisku vezu između ova dva patofiziološka stanja $(70,71)$. NAFLD je bolest koju prati širok spektar stanja: masna jetra (steatoza), naprednija steatoza praćena nekroinflamacijom sa ili bez fibroze tkiva (nealkoholni stetohepatitis), i ozbiljnije bolesti jetre kao što su ciroza i karcinom jetre (72). Pacijenti sa
NAFLD gotovo uvek imaju IR u jetri, koja povećava rizik za razvoj T2DM (70). Povećana sinteza i oslobađanje inflamatornih citokina iz masnog tkiva mogu doprineti razvoju IR $\mathrm{u}$ jetri. $U$ prilog tome idu rezultati studije $\mathrm{u}$ kojoj su korišćeni gojazni miševi (HF ishrana), a kod kojih je došlo do razvoja IR i steatoze jetre, iako koncentracija SMK u portalnoj cirkulaciji nije bila povećana (73). U istoj studiji je zapažena povećana koncentracija citokina, kao što su interleukini, poreklom iz intraperitonealnog masnog tkiva gojaznih miševa. Ranije je pokazano da visceralno masno tkivo gojaznih osoba oslobađa dva do tri puta više interleukina u poređenju sa subkutanim masnim tkivom (74). Tokom gojaznosti i IR dolazi do poremećaja u signalnoj kaskadi IRS/PI3K/ Akt i ekstracelularnim signalima regulisanih kinaza $1 \mathrm{i}$ 2 (ERK1/2, engl. Extracellular Signal-Regulated Kinases 1 and 2) $(52,75,76)$, a samim tim i poremećaja u translokaciji GLUT na plazma membranu (77). Povećana sinteza glukoze u jetri i smanjeno preuzimanje od strane perifernih tkiva dovodi do hiperglikemije (6). Adipociti smanjuju preuzimanje glukoze u perifernim tkivima otpuštajući veliku količinu SMK, koje dodatno stimulišu sintezu glukoze u jetri (46).

\section{ZAKLJUČAK}

Učestalost gojaznosti i pratećih komorbiditeta, uključujući i bolesti jetre, drastično raste poslednjih decenija. Jetra je organ koji je najviše izložen nakupljanju lipida u gojaznosti (78), i predstavlja mesto kompleksne regulacije metabolizma supstrata (glukoze, lipida itd.) od strane insulina i drugih hormona. Mehanizmi kojima gojaznost dovodi do poremećaja metabolizma glukoze i lipida u jetri su danas predmet mnogobrojnih istraživanja (42). S obzirom da poremećaj metaboličkih procesa u jetri u stanju gojaznosti može dovesti do ozbiljnih komplikacija i bolesti jetre, razumevanje ovih bazičnih mehanizama je važno za razvoj novih pristupa u terapiji.

\section{Zahvalnica}

Izrada ovog rada je finansirana sredstvima sa projekata br. 173033 (E.R.I.) od strane Ministarstva za nauku i tehnološki razvoj Republike Srbije.

\section{Literatura}

1. Bradbury, M.W., Lipid metabolism and liver inflammation. I. Hepatic fatty acid uptake: possible role in steatosis. Am J Physiol Gastrointest Liver Physiol, 2006. 290(2): p. G194-8.

2. Fujimoto, M., et al., A role for iNOS in fasting hyperglycemia and impaired insulin signaling in the liver of obese diabetic mice. Diabetes, 2005. 54(5): p. 1340-8

3. Bechmann, L.P., et al., The interaction of hepatic lipid and glucose metabolism in liver diseases. J Hepatol, 2012. 56(4): p. 952-64.

4. Wong, V.W., et al., Disease progression of non-alcoholic fatty liver disease: a prospective study with paired liver biopsies at 3 years. Gut, 2010. 59(7): p. 969-74.

5. McPherson, S., et al., Evidence of NAFLD progression from steatosis to fibrosing-steatohepatitis using paired biopsies: implications for progno- sis and clinical management. J Hepatol, 2015. 62(5): p. 1148-55.

6. Saltiel, A.R. and C.R. Kahn, Insulin signalling and the regulation of glucose and lipid metabolism. Nature, 2001. 414(6865): p. 799-806.

7. Nordlie, R.C., J.D. Foster, and A.J. Lange, Regulation of glucose production by the liver. Annu Rev Nutr, 1999. 19: p. 379-406.

8. Capaldo, B., et al., Splanchnic and leg substrate exchange after ingestion of a natural mixed meal in humans. Diabetes, 1999. 48(5): p. 95866.

9. Ferrannini, E., et al., The disposal of an oral glucose load in healthy subjects. A quantitative study. Diabetes, 1985. 34(6): p. 580-8.

10. Woerle, H.J., et al., Pathways for glucose disposal after meal ingestion in humans. Am J Physiol Endocrinol Metab, 2003. 284(4): p. 10.

11. Charron, M.J., et al., A glucose transport protein expressed predomi- 
nately in insulin-responsive tissues. Proc Natl Acad Sci U S A, 1989. 86(8): p. 2535-9.

12. Hah, J., et al., Demonstration of an insulin-insensitive storage pool of glucose transporters in rat hepatocytes and HepG2 cells. J Cell Physiol, 1992. 152(1): p. 56-63.

13. Aschenbach, J.R., et al., Expression of $m R N A$ for glucose transport proteins in jejunum, liver, kidney and skeletal muscle of pigs. J Physiol Biochem, 2009. 65(3): p. 251-66.

14. Burcelin, R., et al., Liver hyperplasia and paradoxical regulation of glycogen metabolism and glucose-sensitive gene expression in GLUT2-null hepatocytes. Further evidence for the existence of a membrane-based glucose release pathway. J Biol Chem, 2000. 275(15): p. 10930-6.

15. Burcelin, R., W. Dolci, and B. Thorens, Glucose sensing by the hepatoportal sensor is GLUT2-dependent: in vivo analysis in GLUT2-null mice. Diabetes, 2000. 49(10): p. 1643-8.

16. Rencurel, F., et al., Requirement of glucose metabolism for regulation of glucose transporter type 2 (GLUT2) gene expression in liver. Biochem J, 1996. 314(Pt 3): p. 903-9.

17. Wang, H., G. Kouri, and C.B. Wollheim, ER stress and SREBP-1 activation are implicated in beta-cell glucolipotoxicity. J Cell Sci, 2005. 118(Pt 17): p. 3905-15.

18. Raddatz, D. and G. Ramadori, Carbohydrate metabolism and the liver: actual aspects from physiology and disease. Z Gastroenterol, 2007. 45(1): p. 51-62.

19. Giacca, A., et al., Importance of peripheral insulin levels for insulin-induced suppression of glucose production in depancreatized dogs. Journal of Clinical Investigation, 1992. 90(5): p. 1769-1777.

20. Lewis, G.F., et al., Hepatic glucose production is regulated both by direct hepatic and extrahepatic effects of insulin in humans. Diabetes, 1996. 45(4): p. 454-62.

21. Boden, G., P. Cheung, and C. Homko, Effects of acute insulin excess and deficiency on gluconeogenesis and glycogenolysis in type 1 diabetes. Diabetes, 2003. 52(1): p. 133-7.

22. Pilkis, S.J. and D.K. Granner, Molecular physiology of the regulation of hepatic gluconeogenesis and glycolysis. Annu Rev Physiol, 1992. 54: p. 885-909.

23. Ishihara, H., et al., Islet beta-cell secretion determines glucagon release from neighbouring alpha-cells. Nat Cell Biol, 2003. 5(4): p. 330-5.

24. Quesada, I., et al., Physiology of the pancreatic alpha-cell and glucagon secretion: role in glucose homeostasis and diabetes. J Endocrinol, 2008. 199(1): p. 5-19.

25. Obici, S., et al., Hypothalamic insulin signaling is required for inhibition of glucose production. Nat Med, 2002. 8(12): p. 1376-82.

26. LeRoith, D. and O. Gavrilova, Mouse models created to study the pathophysiology of Type 2 diabetes. Int J Biochem Cell Biol, 2006. 38(56): p. 904-12.

27. Sale, E.M. and G.J. Sale, Protein kinase B: signalling roles and therapeutic targeting. Cell Mol Life Sci, 2008. 65(1): p. 113-27.

28. Coffer, P.J., J. Jin, and J.R. Woodgett, Protein kinase B (c-Akt): a multifunctional mediator of phosphatidylinositol 3-kinase activation. Biochem J, 1998. 335(Pt 1): p. 1-13.

29. Manning, B.D. and L.C. Cantley, $A K T / P K B$ signaling: navigating downstream. Cell, 2007. 129(7): p. 1261-74.

30. Holman, G.D. and M. Kasuga, From receptor to transporter: insulin signalling to glucose transport. Diabetologia, 1997. 40(9): p. 991-1003.

31. Bertrand, L., et al., Insulin signalling in the heart. Cardiovasc Res, 2008. 79(2): p. 238-48.

32. Timlin, M.T. and E.J. Parks, Temporal pattern of de novo lipogenesis in the postprandial state in healthy men. Am J Clin Nutr, 2005. 81(1): p. 35-42.

33. Merkel, M., R.H. Eckel, and I.J. Goldberg, Lipoprotein lipase: genetics, lipid uptake, and regulation. J Lipid Res, 2002. 43(12): p. 1997-2006.

34. Berk, P.D. and D.D. Stump, Mechanisms of cellular uptake of long chain free fatty acids. Mol Cell Biochem, 1999. 192(1-2): p. 17-31.

35. Ursula, B., et al., Compartmentation of Hepatic Fatty-Acid-Binding Protein in Liver Cells and Its Effect on Microsomal Phosphatidic Acid Biosynthesis, in Biological Chemistry Hoppe-Seyler1989. p. 229.

36. Hirsch, D., A. Stahl, and H.F. Lodish, A family of fatty acid transporters conserved from mycobacterium to man. Proc Natl Acad Sci U S A,
1998. 95(15): p. 8625-9.

37. Ibrahimi, A. and N.A. Abumrad, Role of CD36 in membrane transport of long-chain fatty acids. Curr Opin Clin Nutr Metab Care, 2002. 5(2): p. 139-45.

38. Delarue, J. and C. Magnan, Free fatty acids and insulin resistance. Curr Opin Clin Nutr Metab Care, 2007. 10(2): p. 142-8.

39. Berk, P.D., Regulatable fatty acid transport mechanisms are central to the pathophysiology of obesity, fatty liver, and metabolic syndrome. Hepatology, 2008. 48(5): p. 1362-76.

40. Wilson, C.G., et al., Hepatocyte-Specific Disruption of CD36 Attenuates Fatty Liver and Improves Insulin Sensitivity in HFD-Fed Mice. Endocrinology, 2016. 157(2): p. 570-85.

41. Koonen, D.P., et al., Increased hepatic CD36 expression contributes to dyslipidemia associated with diet-induced obesity. Diabetes, 2007. 56(12): p. 2863-71.

42. Steneberg, P., et al., The FFA receptor GPR40 links hyperinsulinemia, hepatic steatosis, and impaired glucose homeostasis in mouse. Cell Metab, 2005. 1(4): p. 245-58

43. Bergman, R.N. and M. Ader, Free fatty acids and pathogenesis of type 2 diabetes mellitus. Trends Endocrinol Metab, 2000. 11(9): p. 351-6.

44. Boden, G., Free fatty acids, insulin resistance, and type 2 diabetes mellitus. Proc Assoc Am Physicians, 1999. 111(3): p. 241-8.

45. Bergman, R.N. and S.D. Mittelman, Central role of the adipocyte in insulin resistance. J Basic Clin Physiol Pharmacol, 1998. 9(2-4): p. $205-$ 21.

46. Boden, G., Role of fatty acids in the pathogenesis of insulin resistance and NIDDM. Diabetes, 1997. 46(1): p. 3-10.

47. Griglio, S. and M.I. Malewiak, Hepatic triglyceride storage and ketonemia in rats fed high fat diets. Nutr Metab, 1975. 19(3-4): p. 131-44.

48. Bjorntorp, P., Abdominal obesity and the metabolic syndrome. Ann Med, 1992. 24(6): p. 465-8.

49. Fabbrini, E., et al., Alterations in adipose tissue and hepatic lipid kinetics in obese men and women with nonalcoholic fatty liver disease. Gastroenterology, 2008. 134(2): p. 424-31.

50. Carmiel-Haggai, M., A.I. Cederbaum, and N. Nieto, A high-fat diet leads to the progression of non-alcoholic fatty liver disease in obese rats. FASEB J, 2005. 19(1): p. 136-8.

51. Reaven, G., Syndrome X. Curr Treat Options Cardiovasc Med, 2001 3(4): p. 323-332.

52. Kahn, S.E., R.L. Hull, and K.M. Utzschneider, Mechanisms linking obesity to insulin resistance and type 2 diabetes. Nature, 2006. 444(7121): p. $840-6$

53. McFarlane, S.I., M. Banerji, and J.R. Sowers, Insulin resistance and cardiovascular disease. J Clin Endocrinol Metab, 2001. 86(2): p. 713-8.

54. Sunny, N.E., et al., Excessive hepatic mitochondrial TCA cycle and gluconeogenesis in humans with nonalcoholic fatty liver disease. Cell Metab, 2011. 14(6): p. 804-10.

55. Chung, B.H., et al., Effect of the fat composition of a single meal on the composition and cytotoxic potencies of lipolytically-releasable free fatty acids in postprandial plasma. Atherosclerosis, 1998. 141(2): p. 321-32.

56. Satapati, S., et al., Mitochondrial metabolism mediates oxidative stress and inflammation in fatty liver. J Clin Invest, 2015. 125(12): p. $4447-$ 4462 .

57. Bril, F. and K. Cusi, Nonalcoholic Fatty Liver Disease: The New Com plication of Type 2 Diabetes Mellitus. Endocrinol Metab Clin North Am, 2016. 45(4): p. 765-781.

58. Stanimirovic, J., Polne razlike u regulaciji ekspresije $i$ aktivnosti inducibilne azot-monoksid-sintaze i natrijum-kalijumove pumpe u jetri gojaznih pacova, in Animalna i humana fiziologija2018, Univerzitet u Beogradu: Beograd. p. 118.

59. Kissebah, A.H. and G.R. Krakower, Regional adiposity and morbidity. Physiol Rev, 1994. 74(4): p. 761-811.

60. Bjorntorp, P., „Portal“ adipose tissue as a generator of risk factors for cardiovascular disease and diabetes. Arteriosclerosis, 1990. 10(4): p. 493-6.

61. Exton, J.H., J.G. Corbin, and C.R. Park, Control of gluconeogenesis in liver. IV. Differential effects of fatty acids and glucagon on ketogenesis and gluconeogenesis in the perfused rat liver. J Biol Chem, 1969. 244(15): p. 4095-102. 
62. Bugianesi, E., A.J. McCullough, and G. Marchesini, Insulin resistance: a metabolic pathway to chronic liver disease. Hepatology, 2005. 42(5): p. 987-1000.

63. Mlinar, B., et al., Molecular mechanisms of insulin resistance and associated diseases. Clin Chim Acta, 2007. 375(1-2): p. 20-35.

64. Sowers, J.R., P.S. Sowers, and J.D. Peuler, Role of insulin resistance and hyperinsulinemia in development of hypertension and atherosclerosis. J Lab Clin Med, 1994. 123(5): p. 647-52.

65. Reaven, G.M., H. Lithell, and L. Landsberg, Hypertension and associated metabolic abnormalities--the role of insulin resistance and the sympathoadrenal system. N Engl J Med, 1996. 334(6): p. 374-81.

66. Nolan, J.J., et al., Mechanisms of the kinetic defect in insulin action in obesity and NIDDM. Diabetes, 1997. 46(6): p. 994-1000.

67. Hunter, S.J. and W.T. Garvey, Insulin action and insulin resistance: diseases involving defects in insulin receptors, signal transduction, and the glucose transport effector system. Am J Med, 1998. 105(4): p. 331-45.

68. Reaven, G.M., Banting lecture 1988. Role of insulin resistance in human disease. Diabetes, 1988. 37(12): p. 1595-607.

69. Petersen, K.F. and G.I. Shulman, Pathogenesis of skeletal muscle insulin resistance in type 2 diabetes mellitus. Am J Cardiol, 2002. 90(5A): p. 11G-18G.

70. Tolman, K.G., et al., Spectrum of liver disease in type 2 diabetes and management of patients with diabetes and liver disease. Diabetes Care, 2007. 30(3): p. 734-43.

71. Petersen, K.F., et al., Increased prevalence of insulin resistance and nonalcoholic fatty liver disease in Asian-Indian men. Proc Natl Acad Sci U S A, 2006. 103(48): p. 18273-7.

72. Musso, G., R. Gambino, and M. Cassader, Recent insights into hepatic lipid metabolism in non-alcoholic fatty liver disease (NAFLD). Progress in Lipid Research, 2009. 48(1): p. 1-26.

73. Wueest, S., et al., Inverse regulation of basal lipolysis in perigonadal and mesenteric fat depots in mice. Am J Physiol Endocrinol Metab, 2012. 302(1): p. 11.

74. Fried, S.K., D.A. Bunkin, and A.S. Greenberg, Omental and subcutaneous adipose tissues of obese subjects release interleukin-6: depot difference and regulation by glucocorticoid. J Clin Endocrinol Metab, 1998. 83(3): p. 847-50.

75. Ren, C., et al., A polysaccharide extract of mulberry leaf ameliorates hepatic glucose metabolism and insulin signaling in rats with type 2 diabetes induced by high fat-diet and streptozotocin. Int J Biol Macromol, 2015. 72: p. 951-9.

76. Gao, Y., et al., Effects of D-Pinitol on Insulin Resistance through the PI3K/Akt Signaling Pathway in Type 2 Diabetes Mellitus Rats. J Agric Food Chem, 2015. 63(26): p. 6019-26.

77. Gandhi, G.R., et al., Insulin sensitization via partial agonism of PPAR $\gamma$ and glucose uptake through translocation and activation of GLUT4 in $\mathrm{PI} 3 \mathrm{~K} / \mathrm{p}$-Akt signaling pathway by embelin in type 2 diabetic rats. Biochimica et Biophysica Acta (BBA) - General Subjects, 2013. 1830(1): p. 2243-2255.

78. Yki-Jarvinen, H., Liver fat in the pathogenesis of insulin resistance and type 2 diabetes. Dig Dis, 2010. 28(1): p. 203-9. 